\title{
Conservação pós-colheita de pêssegos com aplicação de revestimentos aditivados de extrato de erva-mate
}

\section{Postharvest conservation of peaches with the use of edible coatings added with yerba mate extract}

\author{
Karla Siebert Sapelli* (D), Cacilda Márcia Duarte Rios Faria1, Renato Vasconcelos Botelho1 \\ ${ }^{1}$ Universidade Estadual do Centro-Oeste (Unicentro), Departamento de Agronomia, Guarapuava/PR - Brasil \\ ${ }^{*}$ Corresponding Author: Karla Siebert Sapelli, Universidade Estadual do Centro-Oeste (Unicentro), Departamento \\ de Agronomia, Rua Simeão Varela de Sá, 03, CEP: 85015-430, Guarapuava/PR - Brasil, \\ e-mail: karlasapellii@gmail.com
}

Cite as: Sapelli, K. S., Faria, C. M. D. R., \& Botelho, R. V. (2020). Postharvest conservation of peaches with the use of edible coatings added with yerba mate extract. Brazilian Journal of Food Technology, 23, e2019044.

https://doi.org/10.1590/1981-6723.04419

\begin{abstract}
Resumo
O objetivo do presente estudo foi verificar o potencial da aplicação de revestimentos à base de fécula de mandioca $(\mathrm{F})$, aditivados de extrato (E) de erva-mate (llex paraguariensis St. Hill), na conservação pós-colheita de pêssegos. Foram utilizados frutos cv. Della Nona e os tratamentos aplicados foram: frutos sem revestimento (Testemunha), frutos com revestimentos à base de fécula de mandioca aditivados de extrato de erva-mate nas concentrações de $0 \mathrm{~g} \mathrm{~L}^{-1}(\mathrm{~F}+0 \% \mathrm{E}), 5 \mathrm{~g} \mathrm{~L}^{-1}(\mathrm{~F}+5 \% \mathrm{E}), 10 \mathrm{~g} \mathrm{~L}^{-1}(\mathrm{~F}+10 \% \mathrm{E})$ e $15 \mathrm{~g} \mathrm{~L}^{-1}(\mathrm{~F}+15 \% \mathrm{E})$. Os frutos foram armazenados por 10 dias a $1{ }^{\circ} \mathrm{C}$, com $95 \%$ de umidade relativa (UR). Para avaliação da qualidade pós-colheita dos frutos, foram realizadas análises físico-químicas, incluindo sólidos solúveis, acidez titulável, perda de massa e firmeza. Para avaliação do efeito in vitro dos revestimentos no crescimento do fungo Monilinia fructicola, agente causal da podridão parda, avaliou-se a germinação de conídios e a área abaixo da curva de crescimento micelial. Para avaliação do controle da podridão parda in vivo, determinou-se incidência (\%) e índice de infecção, e as enzimas peroxidase e polifenoloxidase. Observou-se que o uso de revestimentos reduziu a perda de massa dos frutos em $50 \%$, aumentou o teor de sólidos solúveis e intensificou a coloração vermelha dos frutos, tornando-os mais atraentes ao consumidor. Além disso, houve aumento da atividade da enzima peroxidase em frutos revestidos e o tratamento com aditivo de $15 \%$ de extrato de erva-mate inibiu o desenvolvimento de podridão parda nos pêssegos.
\end{abstract}

Palavras-chave: Prunus persica; Revestimento comestível; llex paraguariensis; Podridão parda.

\begin{abstract}
The present study had the objective of verifying the potential of the application of cassava starch-based coatings (F), supplemented with yerba mate extract (E) (Ilex paraguariensis St. Hill) in the postharvest conservation of peaches. The fruits used were peaches cv. Della Nona and the applied treatments were: uncoated fruits, fruits with cassava starch-based coatings supplemented with yerba mate extract at concentrations of $0 \mathrm{~g} \mathrm{~L}^{-1}(\mathrm{~F}+0 \% \mathrm{E}), 5 \mathrm{~g} \mathrm{~L}^{-1}$ $(\mathrm{F}+5 \% \mathrm{E}), 10 \mathrm{~g} \mathrm{~L}^{-1}(\mathrm{~F}+10 \% \mathrm{E})$ and $15 \mathrm{~g} \mathrm{~L}^{-1}(\mathrm{~F}+15 \% \mathrm{E})$. The fruits were stored for 10 days at $1{ }^{\circ} \mathrm{C}$ with $95 \%$ relative
\end{abstract}


humidity. To evaluate the postharvest quality of fruits, physicochemical analysis was performed, including soluble solids, titratable acidity, weight loss, and firmness. To evaluate the in vitro effect of the coatings on fungus growth Monilinia fructicola, the causal agent of brown rot, conidia germination and the area under the mycelial growth curve were evaluated. In order to evaluate the in vivo brown rot control, the fruits were inoculated with the M. fructicola fungus and evaluated for incidence (\%) and infection index (\%) and the peroxidase and polyphenol oxidase enzymes. The use of coatings reduced the loss of fruit mass by $50 \%$, an increase of soluble solids content and improved the red color of the fruits, making them more attractive to the consumer. In addition, there was an increase of peroxidase enzyme activity in coated fruits and the coating treatment with $15 \%$ of yerba mate inhibited the development of brown rot in peaches.

Keywords: Prunus persica; Edible coating; Ilex paraguariensis; Brown rot.

\section{Introdução}

O pêssego [Prunus persica (L.) Batcsh] é uma cultura frutífera típica de clima temperado e com grande importância na economia mundial, ocupando o oitavo lugar na produção mundial de frutas na safra de 2016/2017 (United States Department of Agriculture, 2017). Por ser um fruto climatérico, o pêssego apresenta alta taxa respiratória e elevada produção de etileno durante o amadurecimento, provocando deterioração acelerada dos frutos e inúmeras transformações bioquímicas, fazendo com que seja um produto de alta perecibilidade (Chitarra \& Chitarra, 2005; Snowden, 2008; Zhang et al., 2009). Estima-se que as perdas pós-colheita de pêssegos chegam a $44,5 \%$ dos frutos e podem ocorrer por perda de água, incidência de patógenos, pragas e controle inadequado do ambiente de armazenamento (Martins et al., 2006).

A podridão parda, causada pelo fungo Monilinia fructicola (Winter) Honey é a principal doença do pessegueiro e pode provocar perdas significativas no campo e na pós-colheita dos frutos, chegando a $80-90 \%$ sob condições favoráveis para o desenvolvimento da doença (Larena et al., 2005). Seu controle é baseado no uso de programa de aplicação de fungicidas em pré e pós-colheita. Porém, essa prática pode resultar em frutos com resíduos, o que os torna menos atrativos ao consumidor e nocivos ao meio ambiente (Spadoni et al., 2015; Zanela et al., 2015).

Dessa forma, tem-se buscado tecnologias alternativas, eficientes e de baixo custo que possam minimizar a deterioração natural resultante da senescência dos frutos e reduzir as perdas em pós-colheita de frutas e hortaliças (Azeredo, 2012). Nesse cenário, as coberturas comestíveis protetoras apresentam-se como alternativa.

Revestimentos ou coberturas protetoras comestíveis podem ser entendidos como camadas delgadas que se formam sobre o fruto, que podem ser consumidas e atuam alterando a composição de sua atmosfera interna, reduzindo as alterações físico-químicas na pós-colheita dos frutos (Pascall \& Lin, 2013).

A fécula de mandioca é um polissacarídeo abundante no Brasil e pode ser produzido e adquirido com baixo custo. Por ser um produto com boa transparência e resistência à troca gasosa, esse material tem sido objeto de estudos para uso em revestimentos comestíveis (Luvielmo \& Lamas, 2012; Oriani et al., 2014). Castro et al. (2017) avaliaram o efeito de revestimentos de quitosana e fécula de mandioca aditivados de ácido salicílico na pós-colheita de mamões cv. Havaí. Frutos sem revestimento apresentaram maior perda de massa na terceira semana de armazenamento, maior índice de maturação na primeira semana, indicando que o uso de filmes de fécula de mandioca, aditivados de ácido salicílico, é uma ferramenta promissora na conservação pós-colheita de mamões sob refrigeração.

Além disso, os revestimentos podem ser aditivados de compostos antimicrobianos, antioxidantes e agentes que retardam o escurecimento enzimático dos tecidos, como extratos de plantas (Azeredo, 2012). Koushesh Saba \& Sogvar (2016) verificaram que o uso de revestimento combinado de carboximetil celulose ( $1 \% \mathrm{p} / \mathrm{v})$, $\mathrm{CaCl}_{2}(0,5 \%)$ e ácido ascórbico (2\%) suprimiu o escurecimento enzimático em fatias de maçã e reduziu as 
mudanças no conteúdo de sólidos solúveis, na acidez titulável e no pH. Fatias revestidas apresentaram menor atividade das enzimas polifenoloxidase e peroxidase.

A erva-mate (Ilex paraguariensis) é uma planta conhecida por seus benefícios à saúde humana (Morais et al., 2009; Berté et al., 2011; Silva et al., 2011), porém poucos trabalhos foram desenvolvidos para avaliar seu potencial na formulação de revestimento e na conservação pós-colheita de produtos hortícolas. Essa espécie apresenta diversas propriedades medicinais, sendo estimulante, devido à cafeína, antioxidante, antimicrobiano e diurético; influencia no metabolismo de lipídios, devido ao efeito das saponinas; reduz gordura abdominal, entre outras (Morais et al., 2009; Berté et al., 2011; Silva et al., 2011). Essas propriedades estão ligadas à presença, no extrato da planta, de ácido clorogênico, na proporção de $42 \%$ das substâncias presentes no extrato, galocatequina (21\%), ácido gálico (11\%), 4,5 dicafeoilquínico (11\%), cafeína (8\%) e teobromina (2\%), o que totaliza $5 \mathrm{~g} \mathrm{~L}^{-1}$ de fenóis totais e $0,35 \mathrm{~g} \mathrm{~L}^{-1}$ de saponinas (Bracesco et al., 2011).

Desta forma, neste trabalho, avaliou-se o uso de revestimentos à base de fécula de mandioca aditivados de extrato de erva-mate (I. paraguariensis St. Hill), na conservação pós-colheita de pêssegos cv. Della Nona.

\section{Material e métodos}

\subsection{Material}

Os pêssegos utilizados foram produzidos no pomar experimental da Universidade Estadual do Centro-Oeste, localizado no município de Guarapuava, Paraná, Brasil. O pomar está localizado nas coordenadas geográficas $25^{\circ} 23^{\prime} \mathrm{S}$ e $51^{\circ} 2^{\prime} \mathrm{O}$ a $1.098 \mathrm{~m}$ de altitude, com clima subtropical mesotérmico úmido, segundo classificação de Köppen (Caviglione et al., 2000). Para realização do experimento, foram utilizados pêssegos cv. Della Nona produzidos durante a safra de 2016/2017 sob sistema orgânico, de plantas com sete anos.

Para formulação dos extratos e revestimentos, a erva-mate utilizada foi previamente coletada, seca e moída pela indústria Lila Alimentos Ltda., situada no município de Guarapuava, Paraná, Brasil. A fécula de mandioca foi obtida em estabelecimento comercial.

\subsection{Preparo das soluções filmogênicas}

O extrato aquoso de erva-mate foi obtido por meio da infusão de $3 \%(\mathrm{p} / \mathrm{v})$ em água destilada, iniciando-se com temperatura ambiente até que a solução atingisse a temperatura de $80^{\circ} \mathrm{C}$. O extrato obtido foi filtrado e resfriado à temperatura ambiente e armazenado em ambiente protegido da luz até seu uso.

Para os revestimentos, utilizou-se a dissolução de 5\% de fécula de mandioca em água destilada e, a partir dessas soluções, os revestimentos foram preparados com a adição de $0,5 \%, 10 \%$ e $15 \%$ da infusão de erva-mate (Medina Jaramillo et al., 2015).

O delineamento experimental utilizado foi inteiramente casualizado (DIC) com cinco tratamentos e cinco repetições, sendo a parcela experimental composta por três frutos. Os tratamentos consistiram na testemunha, sem tratamento, e revestimentos à base de fécula de mandioca aditivados das doses de $0,5 \%, 10 \%$ e $15 \%$ de extrato de erva-mate, como descritos por Medina Jaramillo et al. (2015).

\subsection{Aplicação dos revestimentos e armazenamento}

Os frutos foram colhidos em 14/dez/2016. Após o período de 24 horas em câmara refrigerada a $1 \pm 1{ }^{\circ} \mathrm{C}$ e $95 \%$ de umidade, realizou-se o tratamento dos frutos por imersão nas soluções dos revestimentos durante 30 segundos. Posteriormente, os frutos foram mantidos à temperatura ambiente para escorrimento do excesso de revestimento e secagem dos frutos durante quatro horas. Os frutos foram mantidos a $1 \pm 1{ }^{\circ} \mathrm{C}$ e $95 \%$ de umidade por 10 dias em câmara refrigerada ao abrigo de luz. Para os experimentos de controle in vivo da 
podridão parda em pêssegos, além do tempo de armazenamento em câmara refrigerada, os pêssegos foram mantidos por mais quatro dias a $25^{\circ} \mathrm{C}$ para simulação do período de prateleira.

\subsection{Análises físico-químicas}

Ao início do período de armazenamento e após 10 dias, realizaram-se as seguintes avaliações.

\subsubsection{Perda de massa fresca}

A massa dos frutos foi determinada com o auxílio de uma balança digital M2202 (BEL Equipamentos Analíticos, Piracicaba-SP), realizando-se a pesagem da parcela experimental, composta por três frutos. Os resultados foram expressos em porcentagem em relação ao peso inicial da amostra.

\subsubsection{Firmeza de polpa}

A firmeza de polpa foi avaliada em todos os frutos, retirando-se a casca em dois pontos de lados opostos. A análise foi realizada com auxílio de um penetrômetro digital de frutas (FR-5120, Lutron, Taiwan), equipado com sonda de aço inoxidável de $10 \mathrm{~mm}$ de diâmetro para pêssegos $(\mathrm{P} / 10 \mathrm{~N})$.

\subsubsection{Teor de Sólidos Solúveis (SS)}

O suco utilizado na análise foi obtido da parcela experimental, constituindo uma repetição do tratamento, com uma centrífuga doméstica (Philips Walita, Barueri-SP). A determinação do teor de sólidos solúveis foi obtida com a leitura direta em refratômetro manual digital (Pocket refractometer Pal1, Atago, China).

\subsubsection{Acidez Titulável (AT)}

Foi determinada por titulação potenciométrica dos pêssegos da parcela experimental com solução padronizada de $\mathrm{NaOH} 0,1 \mathrm{~N}$, sendo adotado como ponto final da titulação $\mathrm{pH}=8,1$. Os valores foram expressos em g de ácido cítrico $100 \mathrm{~g}^{-1}$ de polpa.

\subsubsection{Coloração da epiderme}

Foi avaliada com colorímetro digital (Minolta CR 400, Konica Minolta, Japão). Foram realizadas duas leituras em diferentes pontos de cada fruto.

\subsection{Avaliações in vitro}

Para avaliação do efeito in vitro sobre o crescimento micelial de M. fructicola, foi realizada a diluição dos revestimentos no meio de cultura BDA (batata-dextrose-ágar). Os revestimentos foram preparados com a adição do extrato de erva-mate nas doses de $0,10 \%, 20 \%$ e $30 \%$ e diluídos no meio de cultura na proporção de 1:1, constituindo assim os tratamentos de fécula de mandioca aditivada do extrato nas doses de $0,5 \%$, $10 \%$ e $15 \%(\mathrm{p} / \mathrm{v})$, além da testemunha, sem adição de tratamento. Posteriormente, os meios foram autoclavados durante 15 minutos, a $120^{\circ} \mathrm{C}$, na pressão de 1 atm e vertidos em placas de Petri de $90 \mathrm{~mm}$ de diâmetro. Discos miceliais de $5 \mathrm{~mm}$ do fungo $M$. fructicola foram depositados no centro das placas e incubados em câmara de crescimento a $25 \pm 2{ }^{\circ} \mathrm{C}$ e fotoperíodo de 12 horas. As avaliações foram realizadas a cada 24 horas, por meio da tomada das duas medidas perpendiculares do diâmetro do micélio do fungo, com o auxílio de um paquímetro digital, calculando-se os valores médios de cada placa. O crescimento foi avaliado até que um dos tratamentos atingisse o diâmetro total da placa. Calculou-se a área abaixo da curva de crescimento micelial (AACCM), adaptando-se a fórmula de Campbell \& Madden (1990). 
Para a avaliação da germinação de conídios de M. fructicola, foi utilizada uma placa para teste de ELISA. Em cada uma das cavidades da placa, adicionou-se uma alíquota de $40 \mu \mathrm{L}$ de extrato de erva-mate autoclavado nas doses de $10 \%, 20 \%$ e $30 \%$, além da testemunha com água destilada, e $40 \mu \mathrm{L}$ de suspensão de conídios $\left(5 \times 10^{4}\right.$ conídios $\left.\mathrm{mL}^{-1}\right)$. As suspensões ficaram incubadas por 12 horas a $25{ }^{\circ} \mathrm{C}$. Para determinação da porcentagem de germinação de conídios, adicionaram-se $20 \mu \mathrm{L}$ do corante azul algodão de lactofenol. A avaliação foi realizada com o auxílio de microscópio ótico (modelo CX41, marca Olympus ${ }^{\circledR}$, Olympus Corporation, Jiangsu, China) com aumento de 400 vezes, contando-se 100 conídios por repetição. Conídios com tubos germinativos maiores que o comprimento do conídio foram considerados germinados.

\subsection{Avaliação in vivo do controle de podridão parda}

Os frutos foram revestidos e, após 24 horas de armazenamento em câmara refrigerada a $1 \pm 1{ }^{\circ} \mathrm{C}$ e $95 \%$ de umidade, foram inoculados com o patógeno por aspersão da suspensão de esporos na concentração de $3 \times 10^{5}$ esporos $\mathrm{mL}^{-1}$.

Foram avaliadas as seguintes variáveis:

1. Incidência: relação entre o número de frutos com sintomas de podridão parda e o total de pêssegos avaliados, expressa em porcentagem;

2. Índice de infecção: foi avaliado segundo a metodologia de Yang et al. (2014), a partir da incidência e severidade da doença (diâmetro de lesão) causada por M. fructicola. As lesões foram divididas em cinco classes, de acordo com o diâmetro de lesão: $0=$ sem lesão; $1=$ lesão com diâmetro $<10 \mathrm{~mm}$; $2=$ lesão com diâmetro entre 10 e 15 mm; 3= diâmetro de lesão entre 15 e 20 mm, e 4= lesão com diâmetro $>20 \mathrm{~mm}$. O índice de infecção foi calculado utilizando a seguinte Fórmula 1:

$D I=\frac{(1 \times N 1+2 \times N 2+3 \times N 3+4 \times N 4) \times 100}{4 \times N}$

em que: N1, N2, N3 e N4 é o número de lesões de cada classe, respectivamente; N é o número total de pêssegos avaliados.

3. Proteínas: para as análises enzimáticas, o extrato enzimático foi obtido por meio da mistura de $1 \mathrm{~g}$ do material armazenado dos frutos de cada parcela experimental com $4 \mathrm{~mL}$ de tampão fosfato de potássio $50 \mathrm{mM}(\mathrm{pH}=6,0)$. A solução foi centrifugada a $3.920 \mathrm{G}$ por 40 minutos a $4{ }^{\circ} \mathrm{C}$ em centrífuga modelo Universal 320R (Hetticher, Berlim, Alemanha) e o sobrenadante obtido foi considerado como o extrato enzimático. A dosagem de proteínas foi feita pela metodologia de Bradford (1976);

4. Peroxidase de guaiacol (EC 1.11.1.7): para determinar a atividade da enzima peroxidase de guaiacol (POX), adicionaram-se $20 \mu \mathrm{L}$ de extrato enzimático ajustado para $2,8 \mathrm{~mL}$ da solução contendo $525 \mu \mathrm{L}$ de guaiacol $20 \mathrm{mM}$ e $220 \mu \mathrm{L}$ de peróxido de hidrogênio $60 \mathrm{mM}$ ajustado para $100 \mathrm{~mL}$ de tampão fosfato de potássio a $0,01 \mathrm{M}, \mathrm{pH} 5,2$. Em seguida, os tubos foram colocados em banho-maria a $30^{\circ} \mathrm{C}$ por 10 minutos e a absorbância foi medida em espectrofotômetro modelo UV-1800 (Shimadzu Corporation, Kyoto, Japão) a $470 \mathrm{~nm}$ (Urbanek et al., 1991). Uma unidade de peroxidase de guaiacol foi descrita como variação de $1 \mathrm{OD}_{470} \mathrm{mg}^{-1}$ de proteína solúvel $\mathrm{min}^{-1}$;

5. Polifenoloxidase (EC 1.10.3.2): para determinar a atividade enzimática da polifenoloxidase (PPO), adicionaram-se $200 \mu \mathrm{L}$ do extrato enzimático ajustado para $3 \mathrm{~mL}$ da solução contendo tampão fosfato de potássio a $0,1 \mathrm{M}, \mathrm{pH} 6,5$ e $25 \mathrm{mM}$ de catecol. As soluções foram colocadas em banho-maria a $30^{\circ} \mathrm{C}$ por 10 minutos e a absorbância foi medida em espectrofotômetro modelo UV-1800 (Shimadzu Corporation, Kyoto, Japão) a $410 \mathrm{~nm}$ (Gauillard et al., 1993). Os resultados foram expressos em U min ${ }^{-1} \mathrm{mg}$ proteína ${ }^{-1}$.

Para as análises de peroxidase de guaiacol (EC 1.11.1.7) e polifenoloxidase (EC 1.10.3.2), os frutos de cada parcela experimental foram homogeneizados com uma centrífuga doméstica (Philips Walita, Barueri-SP) e armazenados a $-18{ }^{\circ} \mathrm{C}$ até posterior análise. Além disso, retirou-se um pedaço do fruto fresco próximo à 
lesão de podridão parda, sendo que cada pedaço foi congelado em nitrogênio líquido e armazenado a $-18{ }^{\circ} \mathrm{C}$ até posterior análise (Mirto et al., 2018).

\subsection{Análise estatística}

Os dados obtidos foram avaliados quanto à normalidade pelo Teste de Shapiro Wilk, submetidos à análise de variância e, quando significativo, aplicou-se o teste de comparação de médias de Tuckey $(p<0,05)$, sendo as doses submetidas à análise de regressão utilizando o programa estatística SISVAR versão 5.6 (Ferreira, 2014).

\section{Resultados e discussão}

\subsection{Análises físico-químicas}

O uso de revestimentos à base de fécula de mandioca interferiu positivamente em alguns parâmetros de qualidade pós-colheita de pêssegos cv. Della Nona.

Após 10 dias de armazenamento, frutos revestidos apresentaram menor perda de massa (Figura 1A), sendo que os tratamentos $\mathrm{F}+0 \% \mathrm{E}$ e $\mathrm{F}+10 \mathrm{E} \%$ apresentaram redução de aproximadamente $50 \%$ da perda de massa em relação ao tratamento testemunha. Porém, constatou-se menor firmeza para a dose de $0 \%$ de extrato de erva-mate em relação aos demais tratamentos (Figura 1B). Segundo Crisosto (2006), pêssegos com firmeza entre 27 e $36 \mathrm{~N}$ estão prontos para serem comercializados, e de 9 a $14 \mathrm{~N}$, estão prontos para serem consumidos. Portanto, os frutos revestidos continuavam mais firmes do que no ponto ideal para consumo. Nesta pesquisa, podemos observar que o tratamento $\mathrm{F}+0 \% \mathrm{E}$ apresentou menor perda de massa, porém menor firmeza em relação aos demais tratamentos. Frutos com maior perda de massa podem apresentar maior firmeza, pois, ao aplicar forças de punção, os tecidos com menor turgor apresentam maior elasticidade do tecido, o que promove maiores valores de resistência à penetração (Carvalho Filho et al., 2005; Toivonen \& Brummell, 2008).

A migração da água do fruto para o ambiente é o maior fator de perda de massa durante o armazenamento. Os resultados do presente experimento estão de acordo com Fakhouri et al. (2015), que concluíram que o uso de filmes comestíveis formulados com amido de milho + gelatina + plastificante reduziu a perda de massa em uvas cv. Red Crimson durante o armazenamento. Similarmente, Garcia et al. (2012) verificaram que o revestimento de morangos com fécula de mandioca reduziu a perda de massa durante o armazenamento refrigerado. Revestimentos formulados com fécula e amidos reduzem a migração de água, as trocas gasosas, a respiração e a taxa de reações oxidativas, e suprimem desordens fisiológicas (Versino et al., 2016). 


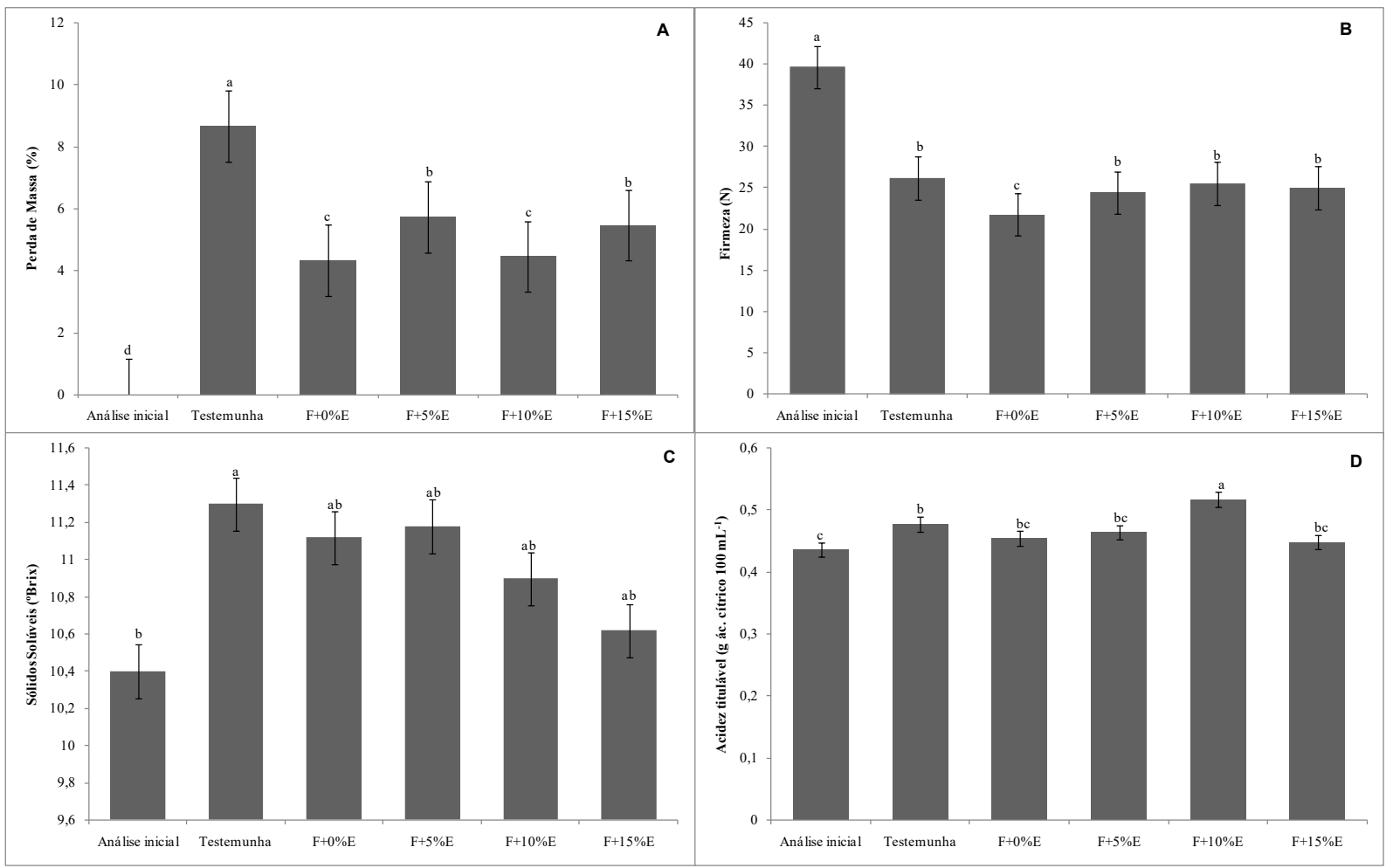

Figura 1. Perda de massa (A), firmeza (B), sólidos solúveis (C) e acidez titulável (D) de pêssegos cv. Della Nona revestidos com diferentes tratamentos* após 10 dias de armazenamento a $1{ }^{\circ} \mathrm{C}$.Médias seguidas pela mesma letra não diferem estatisticamente entre si pelo Teste de Tuckey $(p<0,05)$. Guarapuava-PR, 2017. Barras representam o erro padrão da média. $* \mathrm{~F}+0 \% \mathrm{E}=$ fécula sem adição do extrato de erva-mate; $\mathrm{F}+5 \% \mathrm{E}=$ fécula com adição de $5 \%$ de extrato de erva-mate; $\mathrm{F}+10 \% \mathrm{E}=$ fécula com adição de $10 \%$ de extrato de erva-mate; $\mathrm{F}+15 \% \mathrm{E}=$ fécula com adição de $15 \%$ de extrato de erva-mate.

O teor de sólidos solúveis variou de 10,6 a $11,3^{\circ}$ Brix após 10 dias de armazenamento.Frutos sem revestimentos apresentaram diferenças significativas entre o primeiro e o décimo dia de armazenamento, enquanto que pêssegos revestidos não foram significativamente diferentes e apresentaram acréscimo mais lento no conteúdo de açúcares (Figura 1C). O teor de sólidos solúveis pode ser um índice crítico de maturidade do fruto, pois representa a dinâmica de degradação do amido e o aumento de açúcares solúveis. À medida que ocorre a maturação, há um rápido início de hidrólise do amido, que é utilizado como fonte de energia (Mattiuz et al., 2003). Assim, os resultados do presente estudo demonstram que o uso de revestimentos reduziu a degradação do amido no período de armazenamento.

$\mathrm{O}$ uso de revestimentos que atrasam mudanças no $\mathrm{pH}$ e acidez titulável efetivamente retarda a maturação e senescência; isso ocorre devido à semipermeabilidade do filme formado sobre a superfície do fruto, a qual modifica a atmosfera e a concentração interna de $\mathrm{O}_{2}$ e $\mathrm{CO}_{2}$, retardando o amadurecimento (Mo et al., 2008; Abbasi et al., 2009). A resposta para acidez foi variável para os tratamentos (Figura 1D), porém os frutos do tratamento testemunha e revestidos com $10 \%$ do extrato de erva-mate apresentaram modesto aumento após o período de armazenamento, na ordem de $0,08 \mathrm{~g}$ ácido cítrico $100 \mathrm{~mL}^{-1}$.

A coloração é um importante atributo de qualidade na produção agrícola, principalmente para frutas e hortaliças, e pode determinar o valor do produto (Iglesias \& Echeverría, 2009). Ao avaliar a cromaticidade (Figura 2A), verificou-se que os frutos revestidos apresentaram maiores valores para o parâmetro em relação ao primeiro dia de armazenamento e à testemunha. Entretanto, para a variável ângulo hue (Figura 2B), o contrário foi observado, no presente estudo. $\mathrm{O}$ aumento de cromaticidade e decréscimo no ângulo hue indica intensificação na cor vermelha devido ao amadurecimento dos frutos, tornando-os mais atrativos aos 
consumidores (Borges et al., 2013). Apesar dos indícios de que os tratamentos intensificaram a coloração vermelha, não há dados suficientes para que os resultados sejam conclusivos.

Hazrati \& Hadipour (2016) concluíram que o uso de Aloe vera em gel aumenta os valores de ângulo hue e a cromaticidade de pêssegos durante o armazenamento refrigerado. Eum et al. (2009) constataram que ameixas revestidas ao longo do armazenamento apresentaram redução de hue, o que representa frutos mais vermelhos e escuros devido ao amadurecimento e à senescência. De forma contrastante, Ali et al. (2011) concluíram que o revestimento de mamões com quitosana promove menor aumento do ângulo hue e da cromaticidade ao longo do armazenamento, ou seja, menor desenvolvimento da coloração. Para Dang et al. (2008), mangas revestidas apresentam atraso no desenvolvimento de cor em relação a frutos não revestidos, devido ao aumento do ângulo hue e da cromaticidade.
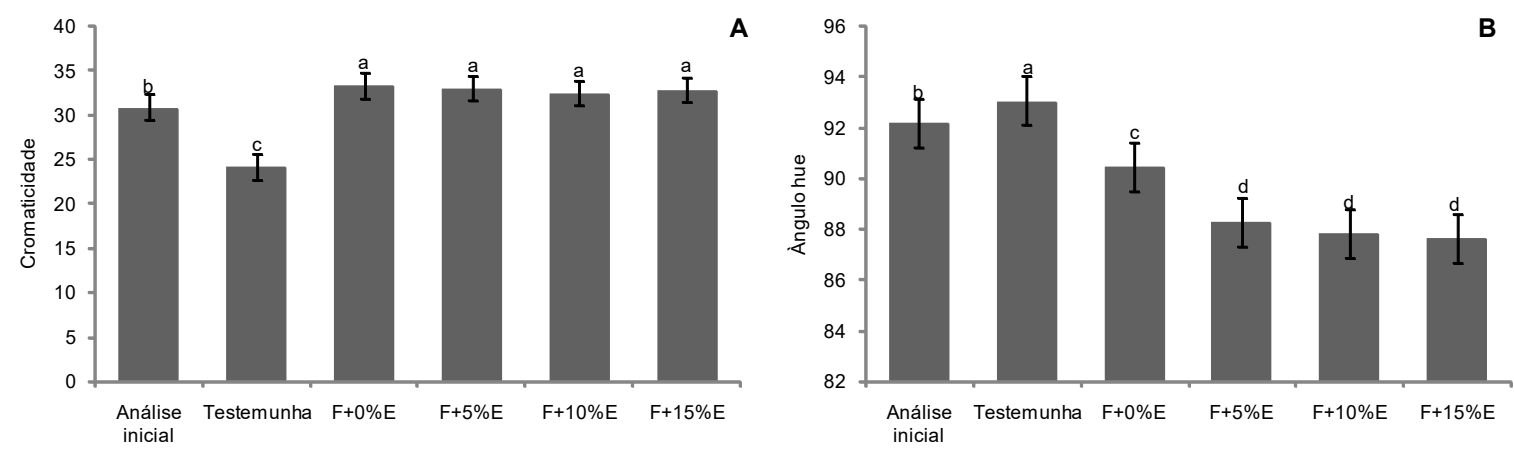

Figura 2. Cromaticidade (A) e ângulo hue (B) de pêssegos cv. Della Nona revestidos com diferentes tratamentos* após 10 dias de armazenamento a $1{ }^{\circ} \mathrm{C}$. Médias seguidas pela mesma letra não diferem estatisticamente entre si pelo Teste de Tuckey $(p<0,05)$. Guarapuava-PR, 2017. Barras representam o erro padrão da média. $* \mathrm{~F}+0 \% \mathrm{E}=$ fécula sem adição do extrato de erva-mate; $\mathrm{F}+5 \% \mathrm{E}=$ fécula com adição de $5 \%$ de extrato de erva-mate; $\mathrm{F}+10 \% \mathrm{E}=$ fécula com adição de $10 \%$ de extrato de erva-mate; $\mathrm{F}+15 \% \mathrm{E}=$ fécula com adição de $15 \%$ de extrato de erva-mate.

\subsection{Avaliações in vitro}

O uso de extrato de erva-mate aumentou o crescimento micelial do fungo M. fructicola para revestimentos com fécula de mandioca em relação à testemunha e houve aumento linear do desenvolvimento do fungo em função das doses de extrato de erva-mate (Figura 3). Saa et al. (2016) avaliaram o desenvolvimento dos fungos Rhizopus stolonifer e Monilinia fructicola, agentes causais da podridão parda em amêndoas, sob diferentes doses de nitrogênio. Assim, os pesquisadores concluíram que altas doses de $\mathrm{N}$ promovem maior incidência da doença estudada. Portanto, os resultados apresentados no presente estudo podem ser justificados pelo alto teor de $\mathrm{N}$ presente em extrato de erva-mate (Borille et al., 2005; Henrique, 2018), nutriente que pode estimular o desenvolvimento do fungo Monilinia fructicola. 




Figura 3. Área abaixo da curva de crescimento micelial (AACCM) do fungo M. fructicola mantido in vitro em meio de cultura BDA e diferentes tratamentos*. Médias seguidas pela mesma letra não diferem estatisticamente entre si pelo Teste de Tuckey $(p<0,05)$. Guarapuava-PR, 2017. Barras representam o erro padrão da média. $* \mathrm{~F}+0 \% \mathrm{E}=$ fécula sem adição do extrato de erva-mate; $\mathrm{F}+5 \% \mathrm{E}=$ fécula com adição de $5 \%$ de extrato de erva-mate; $\mathrm{F}+10 \% \mathrm{E}=$ fécula com adição de $10 \%$ de extrato de erva-mate; $\mathrm{F}+15 \% \mathrm{E}=$ fécula com adição de $15 \%$ de extrato de erva-mate.

O uso de extrato de erva-mate nas doses de 5\% e 10\% reduziu $18 \%$ e $47 \%$, respectivamente, a germinação de conídios em relação à dose de $15 \%$ do extrato (Figura 4). Jumpponen \& Trappe (1998) realizaram estudos com fungos dark septate e observaram que esses fungos apresentavam capacidade de se desenvolver em meios com material vegetal. Segundo os autores, essa capacidade ocorre porque esses microrganismos produzem enzimas hidrolíticas que auxiliam na liberação de nutrientes de fontes orgânicas, como o nitrogênio.



Figura 4. Avaliação da germinação de conídios do fungo M. fructicola sob diferentes tratamentos*. Médias seguidas pela mesma letra não diferem estatisticamente entre si pelo Teste de Tuckey $(p<0,05)$. Guarapuava-PR, 2017. Barras representam o erro padrão da média. $* 0 \% \mathrm{E}=$ sem adição do extrato de erva-mate; $5 \% \mathrm{E}=$ adição de $5 \%$ do extrato de erva-mate; $10 \% \mathrm{E}=$ adição de $10 \%$ do extrato de erva-mate; $15 \% \mathrm{E}=$ adição de $15 \%$ do extrato de erva-mate.

\subsection{Avaliação in vivo do controle de podridão parda}

Para avaliação de incidência, os tratamentos $\mathrm{F}+5 \% \mathrm{E}$ e $\mathrm{F}+15 \% \mathrm{E}$ diferiram estatisticamente da testemunha, sendo que apenas o revestimento de fécula de mandioca aditivado com $15 \%$ de extrato de erva-mate reduziu os valores do parâmetro, inibindo completamente o desenvolvimento do fungo. Houve efeito quadrático em função das doses de erva-mate, sendo que as doses intermediárias tiveram maior incidência da doença nos frutos.

Observou-se diferença estatística dos frutos revestidos em relação à testemunha para o índice de infecção. Os tratamentos $\mathrm{F}+0 \% \mathrm{E}, \mathrm{F}+10 \% \mathrm{E}$ e $\mathrm{F}+15 \% \mathrm{E}$ reduziram significativamente o tamanho das lesões, quando 
comparados com frutos sem revestimento (Figura 5). Segundo Goy et al. (2009), a ação antimicrobiana de coberturas polissacarídeas pode se dar pela interação eletrostática entre o revestimento e as membranas externas dos microrganismos, o que bloquearia nutrientes essenciais ao crescimento microbiano.
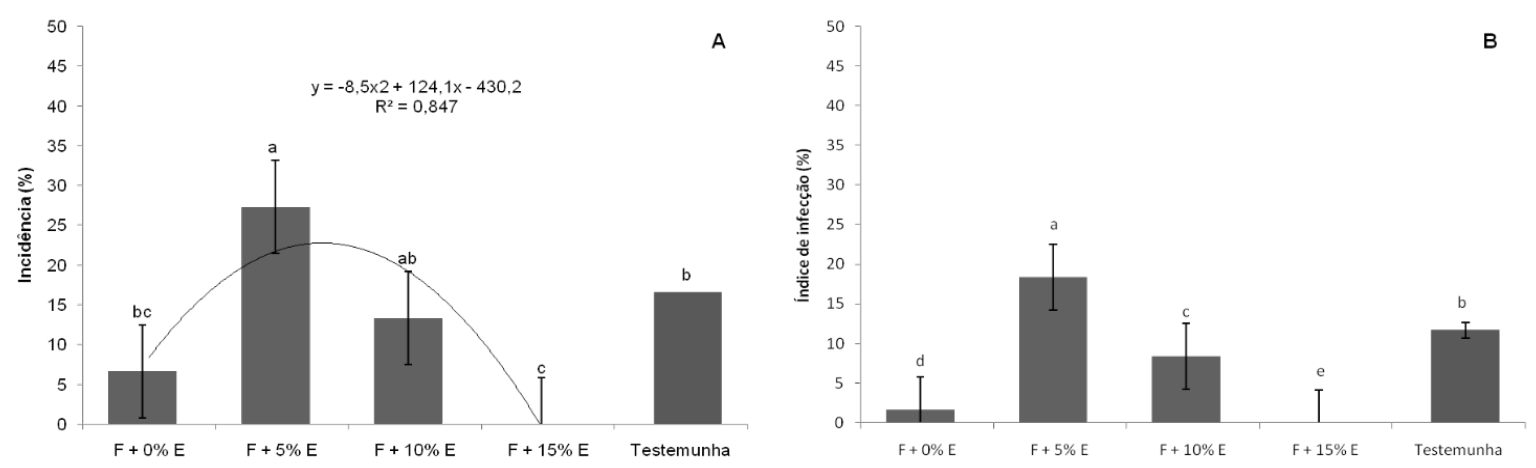

Figura 5. Incidência (\%) (A) e índice de infecção (\%) (B) de frutos revestidos com fécula de mandioca do fungo M. fructicola em pêssegos cv. Della Nona revestidos com diferentes tratamentos* após 20 dias de armazenamento a $1{ }^{\circ} \mathrm{C}+4$ dias a $25^{\circ} \mathrm{C}$. Médias seguidas pela mesma letra não diferem estatisticamente entre si pelo Teste de Tuckey $(p<0,05)$. Guarapuava-PR, 2017. Barras representam o erro padrão da média. ${ }^{*} \mathrm{~F}+0 \% \mathrm{E}=$ fécula sem adição do extrato de erva-mate; $\mathrm{F}+5 \% \mathrm{E}=$ fécula com adição de $5 \%$ de extrato de erva-mate; $\mathrm{F}+10 \% \mathrm{E}=$ fécula com adição de $10 \%$ de extrato de erva-mate; $\mathrm{F}+15 \% \mathrm{E}=$ fécula com adição de $15 \%$ de extrato de erva-mate.

$\mathrm{O}$ uso de revestimento de fécula de mandioca proporcionou aumento da atividade de peroxidase (Figura 6A), sendo que a adição de $10 \%$ de extrato de erva-mate promoveu o aumento da atividade de peroxidase em cerca de 10 vezes em relação à testemunha. A atividade enzimática da polifenoloxidase (Figura 6B) foi influenciada pelos tratamentos, sendo que o uso de fécula de mandioca com $5 \%$ de extrato de erva-mate apresentou maior valor para a variável, diferindo-se dos demais.

A indução de respostas de defesa em interações planta-patógeno leva à formação de espécies reativas de oxigênio (EROs) e ao aumento da atividade enzimática. As EROs agem como sinais de ativação para rotas de resposta às condições de estresse para a planta, ativando o sistema enzimático contra danos oxidativos. As enzimas capazes de eliminar as EROs envolvem a peroxidase, que é responsável pela síntese de lignina e suberina na célula utilizando o $\mathrm{H}_{2} \mathrm{O}_{2}$ como substrato. De acordo com os resultados da presente pesquisa, o aumento da atividade de peroxidase aconteceu em resposta à infecção de $M$. fructicola e ao uso de revestimentos, contribuindo para o reforço da parede celular e o aumento da resistência à penetração de fungos e à incidência de danos mecânicos (Tománková et al., 2006; Torres et al., 2006; Liu et al., 2010; You \& Chan, 2015). Bill et al. (2014) avaliaram a eficácia do uso de revestimentos com adição de óleo de tomilho nos componentes de indução de resistência de frutos de abacate. Os autores verificaram que coberturas formuladas com quitosana e óleo de tomilho reduziram a incidência e severidade de antracnose nos frutos; além disso, o tratamento aumentou a atividade de peroxidase, fenilalanina amônia-liase, $\beta$-1,3-glucanase e quitinase. Segundo Vámos-Vigyázó \& Haard (1981), a enzima polifenoloxidase tem papel importante na resistência de plantas a infecções virais, microbianas e às condições climáticas adversas. De modo geral, as quinonas formadas pela ação da enzima passam por reações de polimerização secundárias, produzindo polímeros escuros e insolúveis. Esses polímeros, presentes nos ferimentos, podem atuar como taninos e formam barreiras físicas no caminho da propagação da infecção.

Wu et al. (2017) concluíram que o uso de cera com cinemaldeído para o controle de podridões na pós-colheita de citros aumentou a atividade da polifenoloxidase; além disso, a atividade enzimática aumentou durante o armazenamento. A polifenoloxidase está associada com respostas de defesa induzida nos frutos. Essa enzima consegue oxidar fenóis em quinonas, o que é extremamente tóxico para patógenos; além disso, esses compostos participam da síntese de lignina e do espessamento da parede celular, auxiliando na resistência a invasão e proliferação microbiana (Lu et al., 2014). 

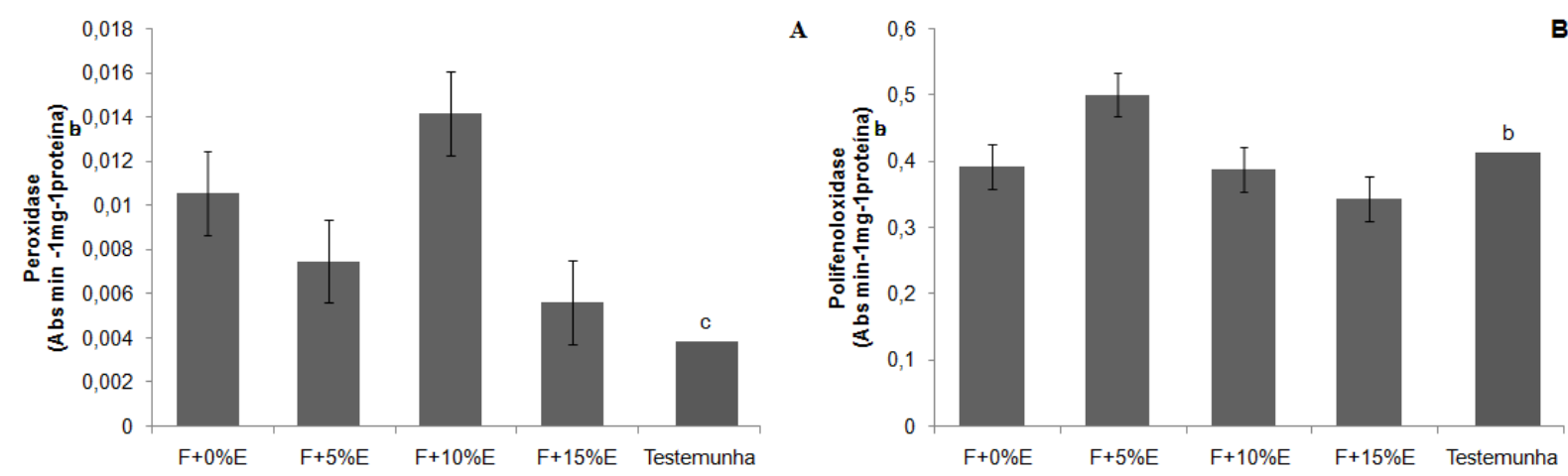

Figura 6. Atividade enzimática de peroxidase (A) e polifenoloxidase (B) em pêssegos cv. Della Nona inoculados com o fungo $M$. fructicola revestidos com diferentes tratamentos* após 20 dias de armazenamento a $1{ }^{\circ} \mathrm{C}+4$ dias a $25^{\circ} \mathrm{C}$. Médias seguidas pela mesma letra não diferem estatisticamente entre si pelo Teste de Tuckey $(p<0,05)$. Guarapuava-PR, 2017. Barras representam o erro padrão da média. $* \mathrm{~F}+0 \% \mathrm{E}=$ fécula sem adição do extrato de erva-mate; $\mathrm{F}+5 \% \mathrm{E}=$ fécula com adição de $5 \%$ de extrato de erva-mate; $\mathrm{F}+10 \% \mathrm{E}=$ fécula com adição de $10 \%$ de extrato de erva-mate; $\mathrm{F}+15 \% \mathrm{E}=$ fécula com adição de $15 \%$ de extrato de erva-mate.

\section{Conclusões}

O uso de revestimento à base de fécula de mandioca foi eficiente na manutenção da qualidade pós-colheita de pêssegos cv. Della Nona, reduzindo a perda de massa e a degradação do amido. Além disso, observaram-se indícios de maior desenvolvimento da coloração vermelha dos frutos, o que foi potencializado com a presença do extrato de erva-mate. As doses intermediárias do extrato apresentaram efeito no controle in vitro do fungo, reduzindo a germinação de conídios. A adição de extrato de erva-mate aumentou a eficiência do tratamento no controle de podridão parda, reduzindo incidência e índice de infecção para a dose de 15\%; além disso, proporcionou aumento da atividade da enzima peroxidase.

\section{Agradecimentos}

À CAPES pela concessão da bolsa durante o período de mestrado.

\section{Referências}

Abbasi, N. A., Iqbal, Z., Maqbool, M., \&Hafiz, I. A. (2009). Postharvest quality of mango (Mangifera indica L.) fruit as affected by chitosan coating. Pakistan Journal of Botany, 41(1), 343-357.

Ali, A., Muhammad, T. M. M., Sijam, K., \&Siddiqui, Y. (2011). Effect of chitosan coatings on the physicochemical characteristics of Eksotika II papaya (Carica papaya L.) fruit during cold storage.Food Chemistry, 124(2), 620-626. http://dx.doi.org/10.1016/j.foodchem.2010.06.085

Azeredo, H. M. C. (2012). Edible coatings. In S.Rodrigues\&F. A. N.Fernandes (Eds.), Advances in fruit processing technologies (Chap. 14, pp. 345-362). Boca Raton: CRC Press. http://dx.doi.org/10.1201/b12088-15.

Berté, K. A. S., Beux, M. R., Spada, P. K. W. D. S., Salvador, M., \&Hoffmann-Ribani, R. (2011). Chemical composition and antioxidant activity of yerba-mate (Ilex paraguariensis A. St.-Hil., Aquifoliaceae) extract as obtained by spray drying. Journal of Agricultural and Food Chemistry, 59(10), 5523-5527. PMid:21510640.http://dx.doi.org/10.1021/jf2008343

Bill, M., Sivakumar, D., Korsten, L., \&Thompson, A. K. (2014). The efficacy of combined application of edible coatings and thyme oil in inducing resistance components in avocado (Persea americana Mill.) against anthracnose during post-harvest storage. Crop Protection, 64, 159-167. http://dx.doi.org/10.1016/j.cropro.2014.06.015

Borges, C. D., Mendonça, C. R. B., Zambiazi, R. C., Silva, E. M. P., \& Paiva, F. F. (2013). Conservação de morangos com revestimentos à base de goma xantana e óleo essencial de sálvia. Bioscience Journal, 29(5), 1071-1083.

Borille, A. M. W., Reissmann, C. B., \&Freitas, R. J. S. (2005). Relação entre compostos fitoquímicos e o nitrogênio em morfotipos de erva-mate (Ilex paraguariensis St. Hil.). Boletim do Centro de Pesquisa e Processamento de Alimentos, 23(1). http://dx.doi.org/10.5380/cep.v23i1.1279

Bracesco, N., Sanchez, A. G., Contreras, V., Menini, T., \& Gugliucci, A. (2011). Recent advances on llex paraguariensis research: Minireview. Journal of Ethnopharmacology, 136(3), 378-384.

PMid:20599603.http://dx.doi.org/10.1016/j.jep.2010.06.032

Bradford, M. M. (1976). A rapid and sensitive method for the quantitation of microgram quantities of protein utilizing the principle of protein-dye binding. Analytical Biochemistry, 72(1-2), 248-254. PMid:942051.http://dx.doi.org/10.1016/0003-2697(76)90527-3 
Campbell, C. L., \& Madden, L. V. (1990). Introduction to plant disease epidemiology. New York: John Wiley \& Sons.

Carvalho Filho, C. D., Honorio, S. L., \& Gil, J. M. (2005). Propriedades mecânicas de cerejas (Prunus avium L.), cv. Ambrunés cobertas com emulsão de cera de carnaúba e zeína. Boletim do Centro de Pesquisa e Processamento de Alimentos, 23(1), 2336. http://dx.doi.org/10.5380/cep.v23i1.1268

Castro, M., Mantuano, M. I., Coloma, J. L., \& Santacruz, S. (2017). Utilisation of cassava starch edible films containing salicylic acid on papaya (Carica papaya L.) preservation. Revista Politécnica, 39(1), 7-12.

Caviglione, J. H., Kijhl, L. R. B., Caramori, P. H., \& Giacomini, C. C. (2000). Cartas climáticas do Paraná. Londrina: IAPAR. Chitarra, M. I. F., \& Chitarra, A. B. (2005). Pós-colheita de frutas e hortaliças: Fisiologia e manuseio (2. ed.). Lavras: UFLA.

Crisosto, C. H. (2006). Peach quality and postharvest technology. Acta Horticulturae, (713), 479-488. http://dx.doi.org/10.17660/ActaHortic.2006.713.72

Dang, K. T., Singh, Z., \& Swinny, E. (2008). Edible coatings influence fruit ripening, quality, and aroma biosynthesis in mango fruit. Journal of Agricultural and Food Chemistry, 56(4), 1361-1370. PMid:18247535.http://dx.doi.org/10.1021/jf072208a

Eum, H. L., Hwang, D. K., Linke, M., Lee, S. K., \& Zude, M. (2009). Influence of edible coating on quality of plum (Prunus salicina Lindl. cv. 'Sapphire'). European Food Research and Technology, 229(3), 427-434. http://dx.doi.org/10.1007/s00217009-1054-8

Fakhouri, F. M., Martelli, S. M., Caon, T., Velasco, J. I., \& Mei, L. H. I. (2015). Edible films and coatings based on starch/gelatin: Film properties and effect of coatings on quality of refrigerated Red Crimson grapes. Postharvest Biology and Technology, 109, 57-64. http://dx.doi.org/10.1016/j.postharvbio.2015.05.015

Ferreira, D. F. (2014). Sisvar: A guide for its Bootstrap procedures in multiple comparisons. Ciência e Agrotecnologia, 38(2), 109-112. http://dx.doi.org/10.1590/S1413-70542014000200001

Garcia, L. C., Pereira, L. M., Sarantópoulos, C. I. G., \& Hubinger, M. D. (2012). Effect of antimicrobial starch edible coating on shelf-life of fresh strawberries. Packaging Technology \& Science, 25(7), 413-425. http://dx.doi.org/10.1002/pts.987

Gauillard, F., Richard-Forget, F., \& Nicolas, J. (1993). New espectrophotometriassay for polyphenol oxidase activity. Activity Biochemistry, 215(1), 59-65. PMid:8297016.

Goy, R. C., Britto, D., \& Assis, O. B. G. (2009). A review of the antimicrobial activity of chitosan. Polímeros, 19(3), 241-247. http://dx.doi.org/10.1590/S0104-14282009000300013

Hazrati, M. K., \& Hadipour, N. L. (2016). Adsorption behavior of 5-fluorouracil on pristine, B-, Si-, and Al-doped C60 fullerenes: A first-principles study. Physics Letters: Part A, 380(7), 937-941. http://dx.doi.org/10.1016/j.physleta.2016.01.020

Henrique, F. A. (2018). Caracterização físico-química da erva mate (Ilex paraguariensis A. St.-Hil) e infusão, comercializada no sul do Brasil propondo critérios de confiabilidade do produto (Dissertação de mestrado). Universidade Estadual de Ponta Grossa, Ponta Grossa.

Iglesias, I., \& Echeverría, G. (2009). Differential effect of cultivar and harvest date on nectarine colour, quality and consumer acceptance. Scientia Horticulturae, 120(1), 41-50. http://dx.doi.org/10.1016/j.scienta.2008.09.011

Jumpponen, A., \& Trappe, J. M. (1998). Dark septate root endophytes: A review with special reference to facultative biotrophic symbiosis. The New Phytologist, 140(2), 295-310. http://dx.doi.org/10.1046/j.1469-8137.1998.00265.x

Koushesh Saba, M., \& Sogvar, O. B. (2016). Combination of carboxymethyl cellulose-based coatings with calcium and ascorbic acid impacts in browning and quality of fresh-cut apples. Lebensmittel-Wissenschaft + Technologie, 66, 165-171. http://dx.doi.org/10.1016/j.Iwt.2015.10.022

Larena, I., Torres, R., De Cal, A., Liñán, M., Melgarejo, P., Domenichini, P., Bellini, A., Mandrin, J. F., Lichou, J., Eribe, X. O., \& Usall, J. (2005). Biological control of postharvest brown rot (Monilinia spp.) of peaches by field applications of Epicoccum nigrum. Biological Control, 32(2), 305-310. http://dx.doi.org/10.1016/j.biocontrol.2004.10.010

Liu, X., Williams, C. E., Nemacheck, J. A., Wang, H., Subramanyam, S., Zheng, C., \& Chen, M. S. (2010). Reactive oxygen species are involved in plant defense against a gall midge. Plant Physiology, 152(2), 985-999.

PMid:19965963.http://dx.doi.org/10.1104/pp.109.150656

Lu, L., Xu, S., Zeng, L., Zheng, X., \& Yu, T. (2014). Rhodosporidium paludigenum induced resistance in Ponkan mandarin against Penicillium digitatum requires ethylene-dependent signaling pathway. Postharvest Biology and Technology, 97, 93-101. http://dx.doi.org/10.1016/j.postharvbio.2014.06.007

Luvielmo, M., \& Lamas, S. M. V. (2012). Revestimentos comestíveis em frutas. Estudos Tecnológicos em Engenharia, 8(1), 815. http://dx.doi.org/10.4013/ete.2012.81.02

Martins, M. C., Lourenço, S. A., Gutierrez, A. S., Jacomino, A. P., \& Amorim, L. (2006). Quantificação de danos pós-colheita em pêssegos no mercado atacadista de São Paulo. Fitopatologia Brasileira, 31(1), 5-10. http://dx.doi.org/10.1590/S010041582006000100001

Mattiuz, B. H., Durigan, J. F., \& Rossi Júnior, O. D. (2003). Processamento mínimo em goiabas 'Paluma' e ‘Pedro Sato': 2. Avaliação química, sensorial e microbiológica. Food Science and Technology, 23(3), 409-413. http://dx.doi.org/10.1590/S010120612003000300020

Medina Jaramillo, C., González Seligra, P., Goyanes, S., Bernal, C., \& Famá, L. (2015). Biofilms based on cassava starch containing extract of yerba mate as antioxidant and plasticizer. Starch, 67(9-10), 780-789. http://dx.doi.org/10.1002/star.201500033

Mirto, A., lannuzzi, F., Carillo, P., Ciarmiello, L. F., Woodrow, P., \& Fuggi, A. (2018). Metabolic characterization and antioxidant activity in sweet cherry (Prunus avium L.) Campania accessions: Metabolic characterization of sweet cherry accessions. Food Chemistry, 240, 559-566. PMid:28946311.http://dx.doi.org/10.1016/j.foodchem.2017.07.162

Mo, Y., Gong, D., Liang, G., Han, R., Xie, J., \& Li, W. (2008). Enhanced preservation effects of sugar apple fruits by salicylic acid treatment during post-harvest storage. Journal of the Science of Food and Agriculture, 88(15), 2693-2699. http://dx.doi.org/10.1002/jsfa.3395 
Morais, E. C., Stefanuto, A., Klein, G. A., Boaventura, B. C., Andrade, F., Wazlawik, E., Di Pietro, P. F., Maraschin, M., \& Silva, E. L. (2009). Consumption of yerba mate (Ilex paraguariensis) improves serum lipid parameters in healthy dyslipidemic subjects and provides an additional LDL-cholesterol reduction in individuals on statin therapy. Journal of Agricultural and Food Chemistry, 57(18), 8316-8324. PMid:19694438.http://dx.doi.org/10.1021/jf901660g

Oriani, V. B., Molina, G., Chiumarelli, M., Pastore, G. M., \& Hubinger, M. D. (2014). Properties of cassava starch-based edible coating containing essential oils. Journal of Food Science, 79(2), E189-E194. PMid:24410449.http://dx.doi.org/10.1111/17503841.12332

Pascall, M. A., \& Lin, S. J. J. (2013). The application of edible polymeric films and coatings in the food industry. Food Processing \& Technology, 4(2), 100-116.

Saa, S., Peach-Fine, E., Brown, P., Michailides, T., Castro, S., Bostock, R., \& Laca, E. (2016). Nitrogen increases hull rot and interferes with the hull split phenology in almond (Prunus dulcis). Scientia Horticulturae, 199, 41-48.

http://dx.doi.org/10.1016/j.scienta.2015.12.027

Silva, R. D. A., Bueno, A. L. S., Gallon, C. W., Gomes, L. F., Kaiser, S., Pavei, C., Ortega, G. G., Kucharski, L. C., \& Jahn, M. P. (2011). The effect of aqueous extract of gross and commercial yerba mate (Ilex paraguariensis) on intra-abdominal and epididymal fat and glucose levels in male Wistar rats. Fitoterapia, 82(6), 818-826.

PMid:21600272.http://dx.doi.org/10.1016/j.fitote.2011.04.011

Snowden, A. L. (2008). Post-harvest diseases and disorders of fruits and vegetables (Vol. 1, General Introduction and Fruits). Boca Raton: CRC Press. http://dx.doi.org/10.1201/b18214

Spadoni, A., Cappellin, L., Neri, F., Algarra Alarcon, A., Romano, A., Guidarelli, M., Gasperi, F., Biasioli, F., \& Mari, M. (2015). Effect of hot water treatment on peach volatile emission and Monilinia fructicola development. Plant Pathology, 64(5), 11201129. http://dx.doi.org/10.1111/ppa.12353

Toivonen, P. M. A., \& Brummell, D. A. (2008). Biochemical bases of appearance and texture changes in fresh-cut fruit and vegetables. Postharvest Biology and Technology, 48(1), 1-14. http://dx.doi.org/10.1016/j.postharvbio.2007.09.004

Tománková, K., Luhová, L., Petřivalský, M., Peč, P., \& Lebeda, A. (2006). Biochemical aspects of reactive oxygen species formation in the interaction between Lycopersicon spp. and Oidium neolycopersici. Physiological and Molecular Plant Pathology, 68(1-3), 22-32. http://dx.doi.org/10.1016/j.pmpp.2006.05.005

Torres, M. A., Jones, J. D., \& Dangl, J. L. (2006). Reactive oxygen species signaling in response to pathogens. Plant Physiology, 141(2), 373-378. PMid:16760490.http://dx.doi.org/10.1104/pp.106.079467

United States Department of Agriculture - USDA. (2017). Fresh peach and cherries: World markets and trade. Washington: USDA. Recuperado em 18 de agosto de 2017, de https://apps.fas.usda.gov/psdonline/circulars/StoneFruit.pdf

Urbanek, H., Kuzniak-Gebarowska, E., \& Herka, H. (1991). Elicitation of defense responses in bean leaves by Botrytis cinerea polygalacturonase. Acta Physiologiae Plantarum, 13, 43-50.

Vámos-Vigyázó, L., \& Haard, N. F. (1981). Polyphenol oxidases and peroxidases in fruits and vegetables. Critical Reviews in Food Science and Nutrition, 15(1), 49-127. http://dx.doi.org/10.1080/10408398109527312

Versino, F., Lopez, O. V., Garcia, M. A., \& Zaritzky, N. E. (2016). Starch-based films and food coatings: An overview. Stärke, 68(11-12), 1026-1037. http://dx.doi.org/10.1002/star.201600095

Wu, Y., Duan, X., Jing, G., Ouyang, Q., \& Tao, N. (2017). Cinnamaldehyde inhibits the mycelial growth of Geotrichum citriaurantii and induces defense responses against sour rot in citrus fruit. Postharvest Biology and Technology, 129, 23-28. http://dx.doi.org/10.1016/j.postharvbio.2017.03.004

Yang, G., Yue, J., Gong, X., Qian, B., Wang, H., Deng, Y., \& Zhao, Y. (2014). Blueberry leaf extracts incorporated chitosan coatings for preserving postharvest quality of fresh blueberries. Postharvest Biology and Technology, 92, 46-53. http://dx.doi.org/10.1016/j.postharvbio.2014.01.018

You, J., \& Chan, Z. (2015). ROS regulation during abiotic stress responses in crop plants. Frontiers in Plant Science, 6 , 1092.PMid:26697045.http://dx.doi.org/10.3389/fpls.2015.01092

Zanela, J., Júnior, A. W., Mazaro, S. M., Citadin, I., \& Luchmann, J. A. (2015). Biofilms in the brown rot control in Eldorado peaches. Applied Research \& Agrotechnology, 7(3), 57-62.

Zhang, M., Leng, P., Zhang, G., \& Li, X. (2009). Cloning and functional analysis of 9-cis-epoxycarotenoid dioxygenase (NCED) genes encoding a key enzyme during abscisic acid biosynthesis from peach and grape fruits. Journal of Plant Physiology, 166(12), 1241-1252. PMid:19307046.http://dx.doi.org/10.1016/j.jplph.2009.01.013 